\title{
Effect of low- and high-linear energy transfer radiation on in vitro and orthotopic in vivo models of osteosarcoma by activation of caspase-3 and -9
}

\author{
EUN HO KIM ${ }^{1}$, MI-SOOK KIM ${ }^{2 *}$, KYUNG-HEE LEE $^{3}$, SEI SAI $^{4}$, \\ YOUN KYOUNG JEONG ${ }^{5}$, JAE-SOO KOH ${ }^{6}$ and CHANG-BAE $\mathrm{KONG}^{3 *}$
}

\begin{abstract}
${ }^{1}$ Division of Heavy Ion Clinical Research, Korea Institute of Radiological and Medical Sciences; Departments of ${ }^{2}$ Radiation Oncology, ${ }^{3}$ Orthopaedic Surgery, Korea Institute of Radiological and Medical Sciences, Seoul 139-706, Republic of Korea; ${ }^{4}$ Department of Basic Medical Sciences for Radiation Damages, National Institute of Radiological Sciences, Chiba, Japan; ${ }^{5}$ Research Center for Radiotherapy, Korea Institute of Radiological and Medical Sciences, ${ }^{6}$ Department of Pathology, Korea Institute of Radiological and Medical Sciences, Seoul 139-706, Republic of Korea
\end{abstract}

Received March 3, 2017; Accepted August 7, 2017

DOI: $10.3892 /$ ijo.2017.4102

\begin{abstract}
Osteosarcoma (OS) is a malignant tumor of the bone derived from primitive transformed cells of the mesenchymal origin. Local low-linear energy transfer (LET) radiotherapy has limited benefits on OS owing to its radioresistance. Thus, this study aimed to investigate the effects of high-LET radiation on human OS. Therefore, the human OS cell lines, $\mathrm{U} 2 \mathrm{O} 2$ and $\mathrm{KHOS} / \mathrm{NP}$, were examined in vitro, or an orthotopic mouse xenograft model was studied in vivo after treatment with low-LET (gamma-ray) and high-LET (neutron) radiation. Notably, OS cells were significantly more sensitive to highLET radiation in vitro and in the orthotopic xenograft tumor model. Specifically, neutron radiation treatment increased the relative percentage of apoptotic sub-G1 phase cells via caspase-3/9 activation; increased intracellular reactive oxygen species, autophagy, and DNA damage; and decreased invasion and migration. Similarly, the mean size of gamma-irradiated (8 Gy) orthotopic KHOS/NP OS was $195 \mathrm{~mm}^{3}$ at 6 weeks after gamma-irradiation ( $8 \mathrm{~Gy}$ ), but it was only $150 \mathrm{~mm}^{3}$ in mice
\end{abstract}

Correspondence to: Dr Mi-Sook Kim, Department of Radiation Oncology, Korea Institute of Radiological and Medical Sciences, Seoul 139-706, Republic of Korea

E-mail: mskim@kirams.re.kr

Dr Chang-Bae Kong, Department of Orthopaedic Surgery, Korea Institute of Radiological and Medical Sciences, Seoul 139-706, Republic of Korea

E-mail: cbkongmd@gmail.com

${ }^{*}$ Contributed equally

Key words: high LET radiation, osteosarcoma cells, apoptosis, DNA damage, orthotopic model treated with high-LET neutron radiotherapy. Significantly, our results provide a rationale for the use of high-LET radiotherapy to treat patients with OS.

\section{Introduction}

Osteosarcomas (OSs) are highly aggressive primary bone tumors of osteoblastic origin that predominantly affect children and young adults (1). Early treatment paradigms in the 1960s entailed aggressive local control with amputation. More recently, a multidisciplinary treatment approach has enhanced both the overall survival and preservation of the organ/limb function (2). Ionizing radiation (IR) therapy is a facet of the modern approach to treat OS (3-6); however, recent reports have emphasized the limited therapeutic efficacy of local low-LET (gamma-radiation) radiotherapy for the treatment of OS, as well as an increased risk of pulmonary metastasis (5-8). Consequently, conventional therapies are unable to prevent metastatic progression in 30-40\% of the patients with OS (9). To generate a more effective and comprehensive treatment methodology, utilization of high-LET radiation might be necessary to treat OS that has become resistant to low-LET radiation. High-LET radiation has several advantages for treating radioresistant human cancers because of its higher relative biological effectiveness (RBE), lower oxygen enhancement ratio (OER), and decreased cell cycle-dependent radiosensitivity. In addition, because cells are less likely to repair radiation-induced damage, charged particle radiation may exert highly lethal effects on radioresistant tumors as compared to conventional low-LET X-ray or gamma-ray irradiations (10-13).

As compared to conventional approaches, carbon ion high-LET radiotherapy is highly efficacious in treating deepseated malignant OSs $(14,15)$. In addition, boron neutron capture therapy (BNCT) has been used to successfully treat a patient with recurrent radiation-induced OS (16). However, the molecular mechanisms underlying carbon ion- or neutroninduced OS cytotoxicity are largely unknown. Therefore, this 
study investigated the therapeutic effects of high-LET neutron radiation on OS in vitro and in vivo.

\section{Materials and methods}

Antibodies and chemicals. Anti-p53 and $\beta$-actin were purchased from Santa Cruz Biotechnology (Santa Cruz, CA, USA). Anticleaved PARP, caspase-3, caspase-9, cleaved caspase-3, cleaved caspase-9, anti-LC3, anti-ATM, anti-p95/NBS1, anti-Ku70, anti-Ku80, anti-DNA-PKcs, and anti-ERCC1 were purchased from Cell Signaling Technology (Danvers, MA, USA), and anti$\gamma$-H2AX was obtained from Millipore (Billerica, MA, USA).

Cell culture. The OS cell lines, U2O2 and KHOS/NP [American Type Culture Collection (ATCC), Rockville, MD, USA], were maintained in $\alpha$ minimum essential medium ( $\alpha$-MEM; Gibco Life Technologies, Carlsbad, CA, USA) supplemented with $10 \%$ (v/v) fetal bovine serum (FBS; Gibco Life Technologies) and 1\% (v/v) penicillin-streptomycin solution (Gibco Life Technologies).

Irradiation. Cells were cultured in $60-$ or $100-\mathrm{mm}$ dishes until $70-80 \%$ confluence at $37^{\circ} \mathrm{C}$ in a humidified atmosphere of $5 \% \mathrm{CO}_{2}$. Irradiations were performed using a ${ }^{137} \mathrm{Cs}$ gamma-ray source (Atomic Energy of Canada, Ltd., Ontario, Canada) at a dose rate of $3.81 \mathrm{~Gy} / \mathrm{min}$. Fast neutrons $(9.8 \mathrm{MeV}$, $30-40 \mathrm{keV} / \mu \mathrm{m}$ ) were produced by the bombardment of proton on beryllium ${ }^{9} \mathrm{Be}(\mathrm{p}, \mathrm{n}){ }^{10} \mathrm{~B}$ as a nuclear reaction in the cyclotron (MC-50; Scanditronix, Uppsala, Sweden). Paired ionization chambers were used to measure the absorbed dose and dose distribution of fast neutron beams or gamma-rays (17). Dosimetric measurements were done before in vitro study to calculate neutron dose using RBE, 2.2, which has been used for neutron therapy in our institute and it showed cell killing efficacy equivalent to that of gamma-ray as determined by clonogenic assay (18).

Colony-forming assay. Cells (500-1000) were seeded into $60-\mathrm{mm}$ dishes in triplicate and stained with $0.4 \%$ crystal violet (Sigma, St. Louis, MO, USA) after 14-20 days to determine plating efficiency (PE), defined as the percentage of seeded cells that formed colonies under the specific culture conditions. The surviving fraction was expressed as a function of irradiation as follows: survival fraction $=$ colonies counted / (cells seeded x PE/100). The plating efficiencies of $\mathrm{U} 2 \mathrm{O} 2$ and $\mathrm{KHOS} / \mathrm{NP}$ cells were $0.48 \pm 0.18$ and $0.34 \pm 0.02$, respectively. $\mathrm{RBE}$ is defined as the ratio of the doses of the two radiations required to cause the effect to the same degree. To evaluate the RBE, the ratio of the doses of the two types of radiations required for similar effect at a survival fraction of $50 \%$ was determined. RBE was evaluated and calculated as the dose (Gy) for gamma-ray radiation divided by the dose for neutron radiation that yielded a surviving fraction of $50 \%$ (D50).

Water-soluble tetrazolium (WST-1) assay. For the cytotoxicity assay, cells were seeded in 96-well culture plastic plates at a density of $1 \times 10^{3}$ cells per well. Each well was exposed to radiation at varying doses (0-5 Gy) and the cells were incubated for $72 \mathrm{~h}$, followed by application of the water-soluble tetrazolium
(WST)-1 cytotoxicity assay reagent (Roche Diagnostics, Laval, Quebec, Canada) according to the manufacturer's recommendations. Cell viability was assessed by determining the A450 nm of the cell culture media after addition of WST-1 for $2 \mathrm{~h}$. The results are reported as a percentage of the optical density of the untreated control cells, which was designated as $100 \%$ cell viability. Percentage of cytotoxicity was calculated as (1-Aexp/Acon) x100, where Aexp and Acontrol are the absorbance values of the experimental IR-treated and control untreated cells, respectively.

Analysis of cell cycle progression. Cells were seeded in 60-mm dishes at $60 \%$ confluency. After $24 \mathrm{~h}$, cells were trypsinized, harvested, and fixed in $1 \mathrm{ml} 70 \%$ cold ethanol in test tubes and then incubated at $4^{\circ} \mathrm{C}$ overnight. The fixed cells were centrifuged at 2,000 rpm for $3 \mathrm{~min}$, and the pellets were resuspended in $500 \mu \mathrm{l}$ propidium iodine $(10 \mu \mathrm{g} / \mathrm{ml})$ containing $300 \mu \mathrm{g} / \mathrm{ml}$ RNase (Sigma). Cell cycle distribution was determined using 10,000 cells with CellQuest ${ }^{\mathrm{TM}}$ software using a FACSCaliber flow cytometer (Becton Dickinson, San Jose, CA, USA).

Detection of apoptotic cells by Annexin V staining. Cells were irradiated and subsequently incubated for $48 \mathrm{~h}$. Cells $\left(1 \times 10^{6}\right.$ cells $\left./ \mathrm{ml}\right)$ were then washed with ice-cold PBS, trypsinized, and resuspended in $1 \mathrm{X}$ binding buffer $[10 \mathrm{mM}$ HEPES/ $\mathrm{NaOH}$ (pH 7.4), $140 \mathrm{mM} \mathrm{NaCl}$, and $2.5 \mathrm{mM} \mathrm{CaCl}_{2}$ ]. Aliquots (100 $\mu \mathrm{l}$ ) of the cell solution were mixed with $5 \mu \mathrm{l}$ Annexin V/ fluorescein isothiocyanate (FITC) (BD Biosciences, Franklin Lakes, NJ, USA) and $10 \mu \mathrm{l}$ propidium iodide (PI) stock solution $(50 \mu \mathrm{g} / \mathrm{ml}$ in PBS) by gentle vortexing, followed by 15-min incubation at room temperature under dark conditions. Next, $400 \mu \mathrm{l} 1 \mathrm{X}$ binding buffer was added to each sample, and the samples were analyzed on a FACScan ${ }^{\mathrm{TM}}$ flow cytometer (BD Biosciences). A minimum of 10,000 cells were counted for each sample, and data were analyzed using CellQuest ${ }^{\mathrm{TM}}$ software (BD Biosciences).

Western blotting. Irradiated OS cells were cultured and then lysed with RIPA buffer. Proteins were separated by SDS-PAGE and transferred onto nitrocellulose membranes. The membranes were blocked with $1 \%(\mathrm{v} / \mathrm{v})$ nonfat dry milk in Tris-buffered saline with $0.05 \%$ Tween-20 and incubated with the indicated primary and secondary antibodies (1:1,000 and 1:5,000 dilution, respectively). Immunoreactive protein bands were visualized by enhanced chemiluminescence (Amersham Biosciences, Little Chalfont, UK).

Caspase activity. Caspase-3 and -9 activities were determined by using detection kits (R\&D Systems, Minneapolis, MN, USA). The assay is based on spectrophotometric detection of the chromophore $p$-nitroanilide ( $p \mathrm{NA}$ ) after cleavage from the labeled substrates of DEVD- $p$ NA (for caspase-3) and LEHD- $p$ NA (for caspase-9). The $p$ NA light emission can be quantified using a spectrophotometer or microtiter plate reader at $405 \mathrm{~nm}$. Comparison of the $p \mathrm{NA}$ absorbance of apoptotic and control samples allows determination of the fold increase in caspase activity.

Intracellular reactive oxygen species detection. Reactive oxygen species (ROS) were monitored using the fluorescent 

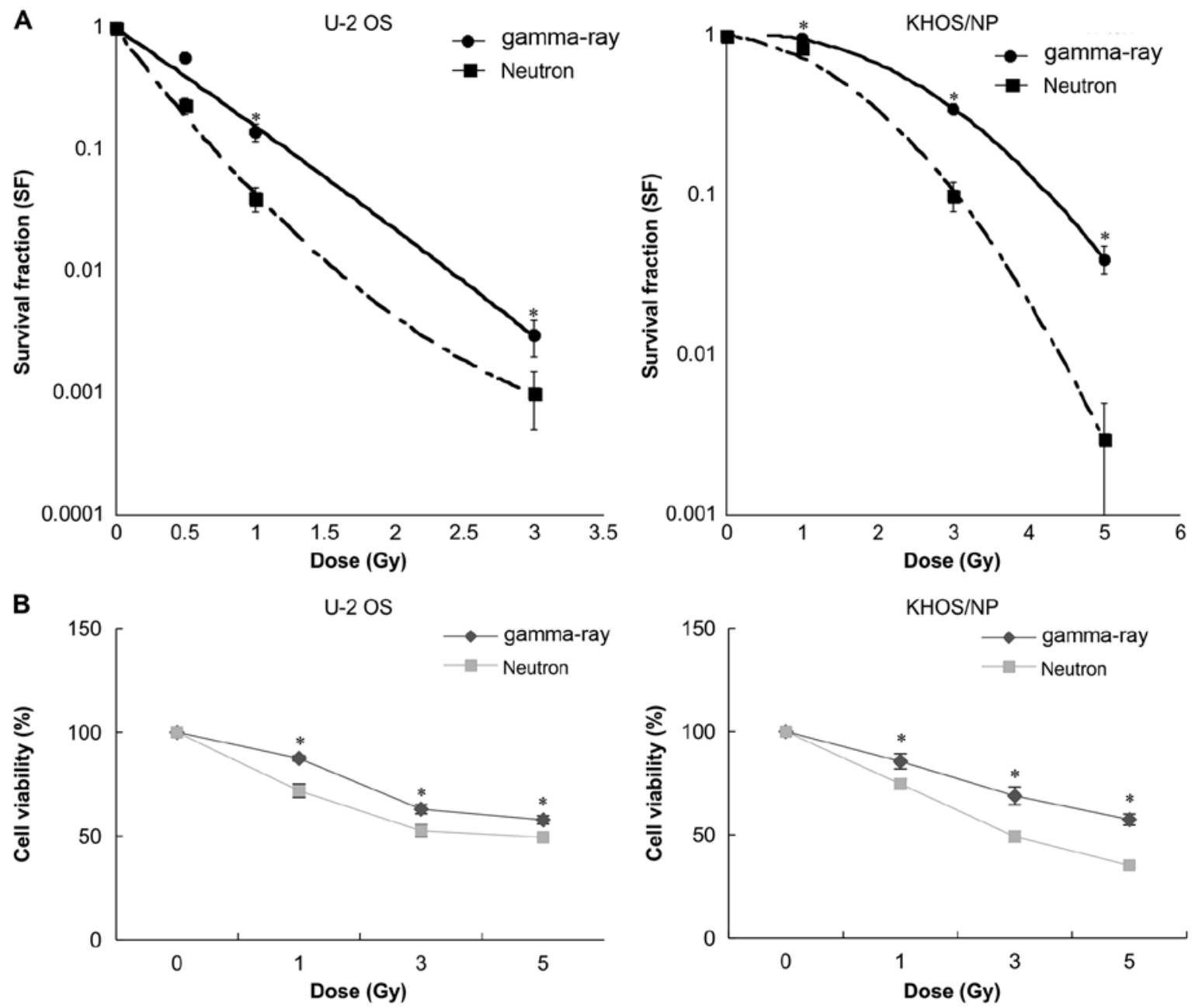

Figure 1. The radiation effects of high LET on OS cells. (A) Radiosensitivity of U2O2 and KHOS/NP cell lines after various doses of gamma-ray and neutron radiation was measured by colony forming assay. Asterisks $(*)$ indicate values that are statistically significant in comparison to radiation-treated cells. Values represent means of 3 experiments $\pm \mathrm{SD}$; ${ }^{*} \mathrm{P}<0.05$. (B) Cell viability of two OS cell lines treated with gamma-ray and neutron for $72 \mathrm{~h}$ was measured by the WST-1 assay. Values represent means of 3 experiments $\pm \mathrm{SD} ;{ }^{*} \mathrm{P}<0.05$.

ROS indicator, $\mathrm{C} 2$ ',7'-dichlorodihydrofluorescein diacetate ( $\mathrm{H}_{2} \mathrm{DCFDA} ; 5 \mu \mathrm{M}$; Molecular Probes, Eugene, OR, USA). Cell-associated fluorescence was detected by FACS using a FACSort ${ }^{\mathrm{TM}}$ flow cytometer with CellQuest software (BD Biosciences).

Quantitative detection of acid vesicular organelles by acridine orange staining. Autophagy is the process of sequestrating cytoplasmic proteins and organelles into the lysosomal component and is characterized by development of acid vesicular organelles (AVOs). To detect and quantify AVOs in IR-treated cells, we performed vital staining with acridine orange (Polysciences, Warrington, PA, USA) as previously described. $\mathrm{U} 2 \mathrm{OS}$ and KHOS/NP cells were stained with $1.0 \mu \mathrm{g} / \mathrm{ml}$ acridine orange for $15 \mathrm{~min}$ at room temperature and processed for flow cytometry using the FACScan cytometer and analyzed with CellQuest software (Becton Dickinson).

Immunocytochemistry. Immunocytochemistry was performed to determine the nuclear distribution of $\gamma-\mathrm{H} 2 \mathrm{AX}$ in individual cells. Cells were grown on chambered slides for 1 day prior to IR. After exposure, cells were irradiated and incubated for 1 or $24 \mathrm{~h}$. All treatments were performed while cells remained attached to the slides, followed by fixation with $4 \%(\mathrm{w} / \mathrm{v})$ paraformaldehyde and permeabilization with $0.5 \%$ (v/v) Triton ${ }^{\mathrm{TM}} \mathrm{X}-100$ in PBS. Detection was performed after the slides were blocked in $10 \%$ (v/v) FBS/1\% (v/v) bovine serum albumin for $1 \mathrm{~h}$, followed by incubation with a 1:1,000 dilution of FITC-labeled mouse monoclonal antibody against $\gamma$-H2AX (Millipore).

Wound healing (scratch) assay. Human OS cells were seeded onto 6-well plates (Corning) at a density of $2.5 \times 10^{4}$ cells/well, $3 \mathrm{ml}$ medium was added, and the cells were irradiated. On day 2 , the monolayers were mechanically disrupted with a sterile $200-\mu 1$ pipette tip. The assay was performed in duplicates, and wells were photographed every $48 \mathrm{~h}$ prior to staining with $0.2 \%(\mathrm{w} / \mathrm{v})$ crystal violet. Cell migration was monitored using an Eclipse Ti microscope with a DS-Fil camera (Nikon, Tokyo, Japan). The cells were counted using ImageJ (US National Institutes of Health, Bethesda, MD, USA).

Transwell chamber assay. The in vitro invasive ability of OS cells was measured using transwell chambers according to the 
manufacturer's protocol. Briefly, cells were seeded onto the membrane of the upper chamber of the transwell at a density of $4 \times 10^{5} / \mathrm{ml}$ in $150 \mu \mathrm{l}$ medium and were left untreated or irradiated with IR for $24 \mathrm{~h}$. The medium in the upper chamber was serum-free, whereas the medium in the lower chamber contained $10 \%(\mathrm{v} / \mathrm{v}) \mathrm{FBS}$ as a source of chemoattractants. Cells that passed through the Matrigel ${ }^{\circledR}$-coated membrane were stained with cell stain solution containing crystal violet supplied in the Transwell chamber assay (Chemicon; Millipore) and photographed after $24 \mathrm{~h}$ of incubation.

Orthotopic model and histological analysis. Twelve 4-week-old female BALB/c nude mice (average body weight, $12.1 \mathrm{~g}$; range 11.3-13.1 g) were obtained from Orient Bio Inc. (Seoul, Korea) and quarantined for 1 week prior to experimentation. KHOS/NP orthotopic tumors were established as previously described (19).

Cells were implanted into the tibias of mice anesthetized by intraperitoneal injection of Zoletil (Virbac, Carros, France) and Roumpun (Bayer Korea, Seoul, Korea). Briefly, the left tibia was wiped with $70 \%$ (v/v) ethanol and an 18-gauge needle was inserted through the tibial plateau with the knee flexed. Then, $1 \times 10^{5} \mathrm{KHOS} / \mathrm{NP}$ cells in $10 \mu \mathrm{l}$ PBS were injected into the marrow space of the proximal tibia with a 26-gauge needle coupled with a Hamilton syringe. Two weeks after OS cell inoculation, mice were randomly assigned into IR or control groups ( $\mathrm{n}=4 /$ group). IR was given as a single dose of $8 \mathrm{~Gy}$ of low-LET gamma-ray or high-LET neutron radiotherapy. Animals were sacrificed 6 weeks after inoculation by $\mathrm{CO}_{2}$ asphyxiation. Tumor length (L) and width (W) were measured with calipers after their sacrifice and used to calculate tumor volume as follows: volume $=\left(\mathrm{Lx} \mathrm{W}^{2}\right) / 2$. All experimental protocols were approved by the Institutional Animal Care and Use Committee of the Korea Institute of Radiological and Medical Sciences. Histological analysis was performed using hematoxylin and eosin (H\&E)-stained paraffin sections $(20,21)$.

Statistical analysis. All analyses were performed by Student's t-test. $\mathrm{P}<0.05$ was considered to indicate a statistically significant difference.

\section{Results}

U2OS and KHOS/NP clonogenicity following gammaray or neutron irradiation. $\mathrm{U} 2 \mathrm{O} 2$ and $\mathrm{KHOS} / \mathrm{NP} \mathrm{OS}$ clonogenic survival decreased as a function of exposure to gamma-ray or neutron irradiation dose (Fig. 1). The results of the colony-forming assay of irradiated KHOS/NP cells are shown in Fig. 1A in the form of survival curves. The surviving fraction (S/S0) data for irradiated OS cells were fitted with the linear quadratic dose (D)-dependent relation given by $\mathrm{S} / \mathrm{S} 0=\exp -\left(\alpha \mathrm{D}+\beta \mathrm{D}^{2}\right)$, where $\alpha$ and $\beta$ are constants. The fitted values of $\alpha$ and $\beta$ for irradiated KHOS/ NP cells are provided in Table I. RBE depends on the dose and the biological endpoints. The average endpoint D50 for $\mathrm{U} 2 \mathrm{O} 2$ and KHOS/NP cells was 0.81 and 3.11 Gy for gammairradiation, and 0.45 and $2.01 \mathrm{~Gy}$ for neutron irradiation, respectively (Table II). Similarly, the dose ratio required for attaining D50 with gamma-ray or neutron irradiation
Table I. Fitting parameters $\alpha$ and $\beta$ for survival assay data.

\begin{tabular}{llcc}
\hline Cell type & Radiation type & $\alpha\left(\mathrm{Gy}^{-1}\right)$ & $\beta\left(\mathrm{Gy}^{-1}\right)$ \\
\hline U2OS & gamma-ray & $0.182 \pm 1.260$ & $0.042 \pm 0.447$ \\
& Neutron & $3.552 \pm 1.258$ & $0.416 \pm 0.445$ \\
KHOS/NP & gamma-ray & $0.097 \pm 0.728$ & $0.148 \pm 0.162$ \\
& Neutron & $0.107 \pm 0.729$ & $0.212 \pm 0.164$ \\
\hline
\end{tabular}

Table II. Radiation dose required for $50 \%$ cytotoxicity and relative biological effectiveness (RBE) values (data extracted from Fig. 1).

\begin{tabular}{llll}
\hline Cell type & Radiation type & D50 & RBE \\
\hline U2OS & gamma-ray & 0.81 & 1.80 \\
& Neutron & 0.45 & \\
KHOS/NP & gamma-ray & 3.11 & 1.55 \\
& Neutron & 2.01 & \\
\hline
\end{tabular}

is extracted from Fig. 1A and summarized in Table II. The values from the fitted curves suggest that as compared to that of gamma-ray irradiation, neutron irradiation was far more effective in reducing the survival fraction. Additionally, U2OS cells showed more radiosensitive than KHOS/NP cells. Therefore, the RBE values of neutron irradiation relative to gamma-ray irradiation were 1.80 and 1.55 , respectively, indicating that the neutron beam exerts more effective cell killing effects compared to the gamma-ray irradiation. The two OS cell lines were also subjected to cell viability analysis by WST-1 assay after either form of irradiation (Fig. 1B), which verified that neutron irradiation had a more potent radiosensitizing effect.

Effect of low-or high-LET IR-induced apoptosis and cell cycle. We next analyzed the effects of gamma-ray and neutron irradiation on cell cycle progression using flow cytometry to assess the relative changes in apoptotic sub-G1 cells. Notably, neutron irradiation resulted in a higher overall increase in sub-G1 cells than that in gamma-raytreated counterparts in a time-dependent manner (Fig. 2A). To determine the fraction of OS cells induced to undergo apoptosis by the radiation treatment, we detected apoptosis by Annexin V and PI staining. Notably, $48 \mathrm{~h}$ treatment with neutron increased the percentage of early apoptotic cells as compared to that after treatment with gamma-ray in the two OS cell lines (Fig. 2B). Cleavage-induced caspase activation is a defining characteristic of apoptotic cell death (22). Therefore, we examined caspase- 3 and caspase- 9 expression and cleavage by western blotting. As shown in Fig. $2 \mathrm{C}$, cell irradiation resulted in increased caspase- 3 and -9 expression in OS cells, with a more potent effect observed with neutron radiation. Caspase-3 activation leads to PARP-1 cleavage (23). As expected, western blot analysis showed a marked increase in cleaved PARP-1 level up to $48 \mathrm{~h}$ after 
A

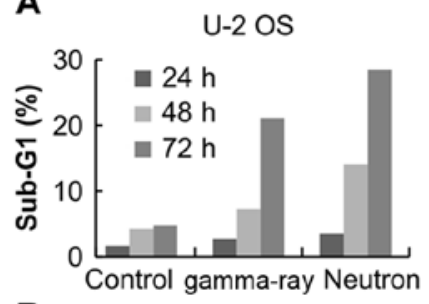

B
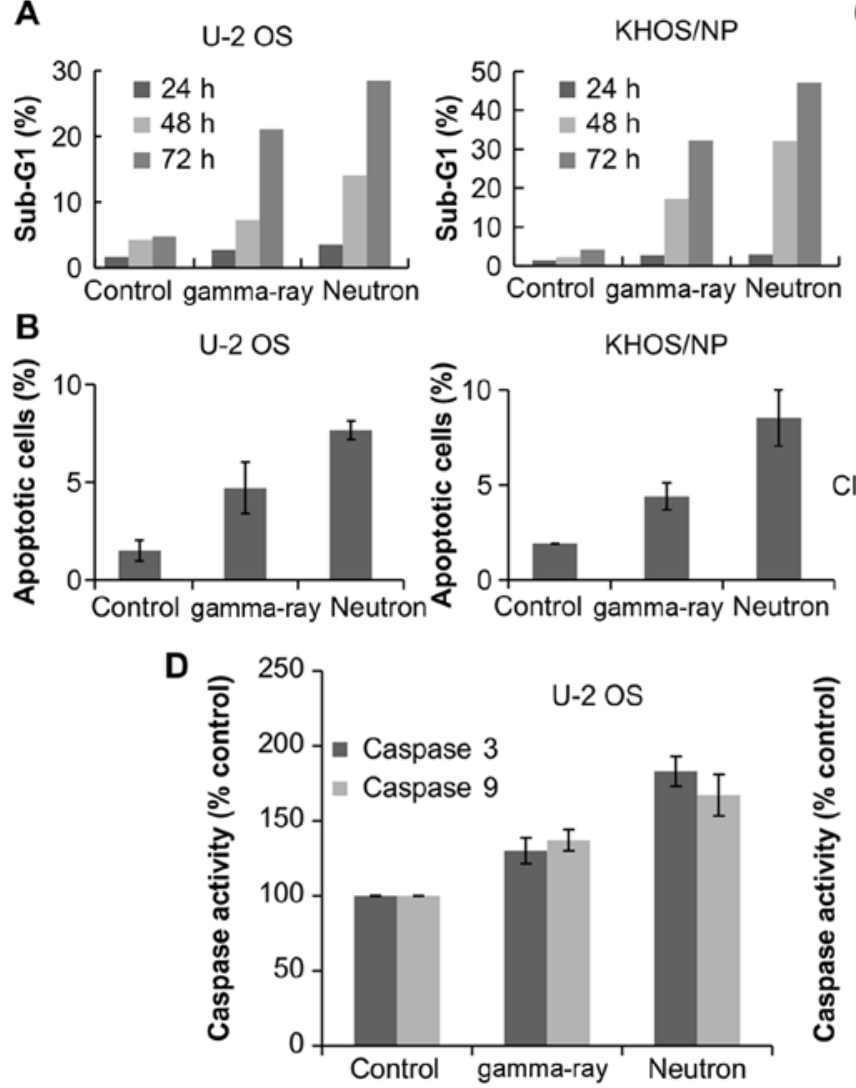

C

$\mathrm{U}-2 \mathrm{OS}$
$48 \mathrm{~h}$

Control gamma-ray Neutron Control gamma-ray Neutron

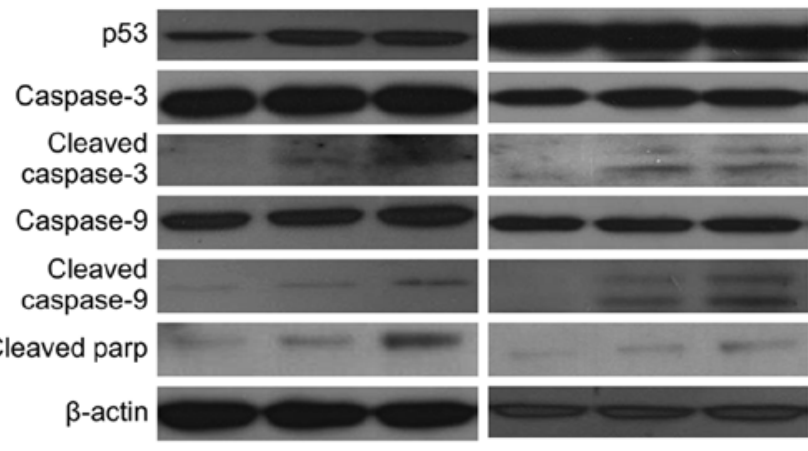

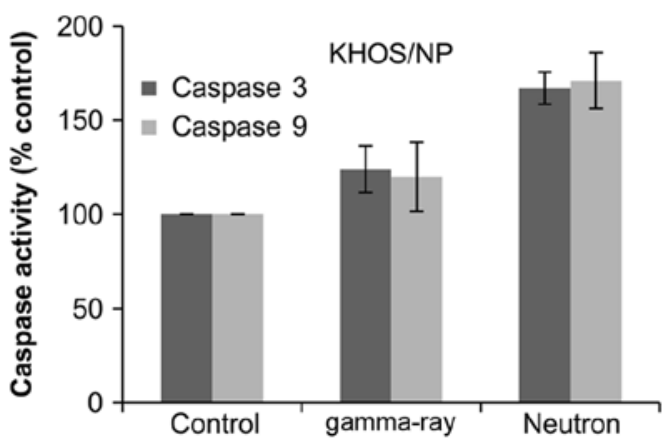
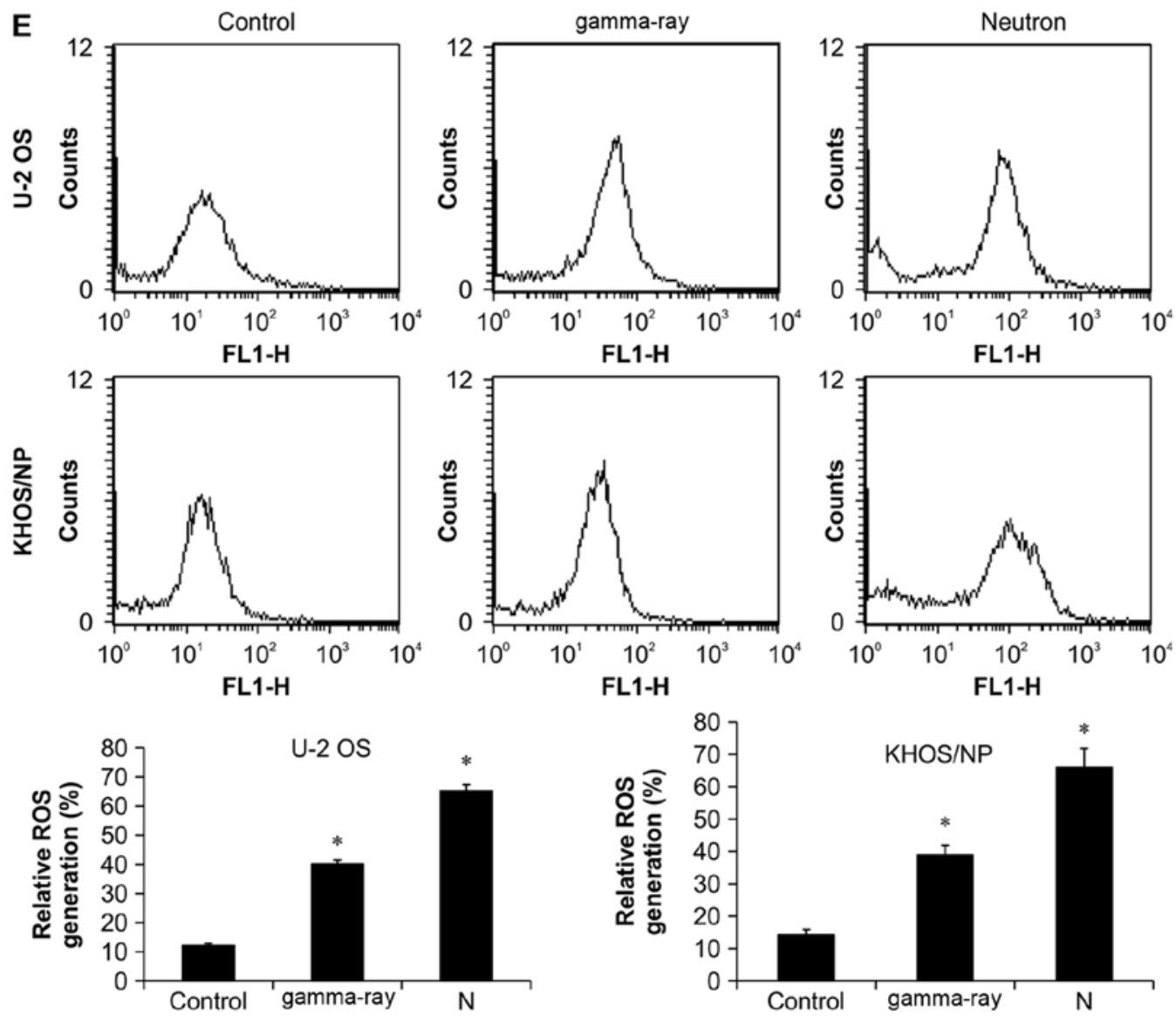

Figure 2. Effects of radiation on apoptosis and cell cycle in OS cells. (A) U2O2 and KHOS/NP cells were treated with 5 Gy gamma-ray and neutron radiation for indicated time points. The cell cycle distribution of sub-G1 was analyzed quantitatively. (B) After 48 h of treatment, U2O2 and KHOS/NP cells were subjected to Annexin V and PI staining and analyzed by flow cytometry. (C) Cell lysates (30 $\mu \mathrm{g}$ ) were immunoblotted (IB) with indicated antibodies. (D) Caspase activities in OS were determined (see Materials and methods). Data are expressed as \% of control and are means \pm SE for 3 experiments. (E) ROS concentration measured at $48 \mathrm{~h}$ after treatment with radiation. ${ }^{*} \mathrm{P}<0.05$. 

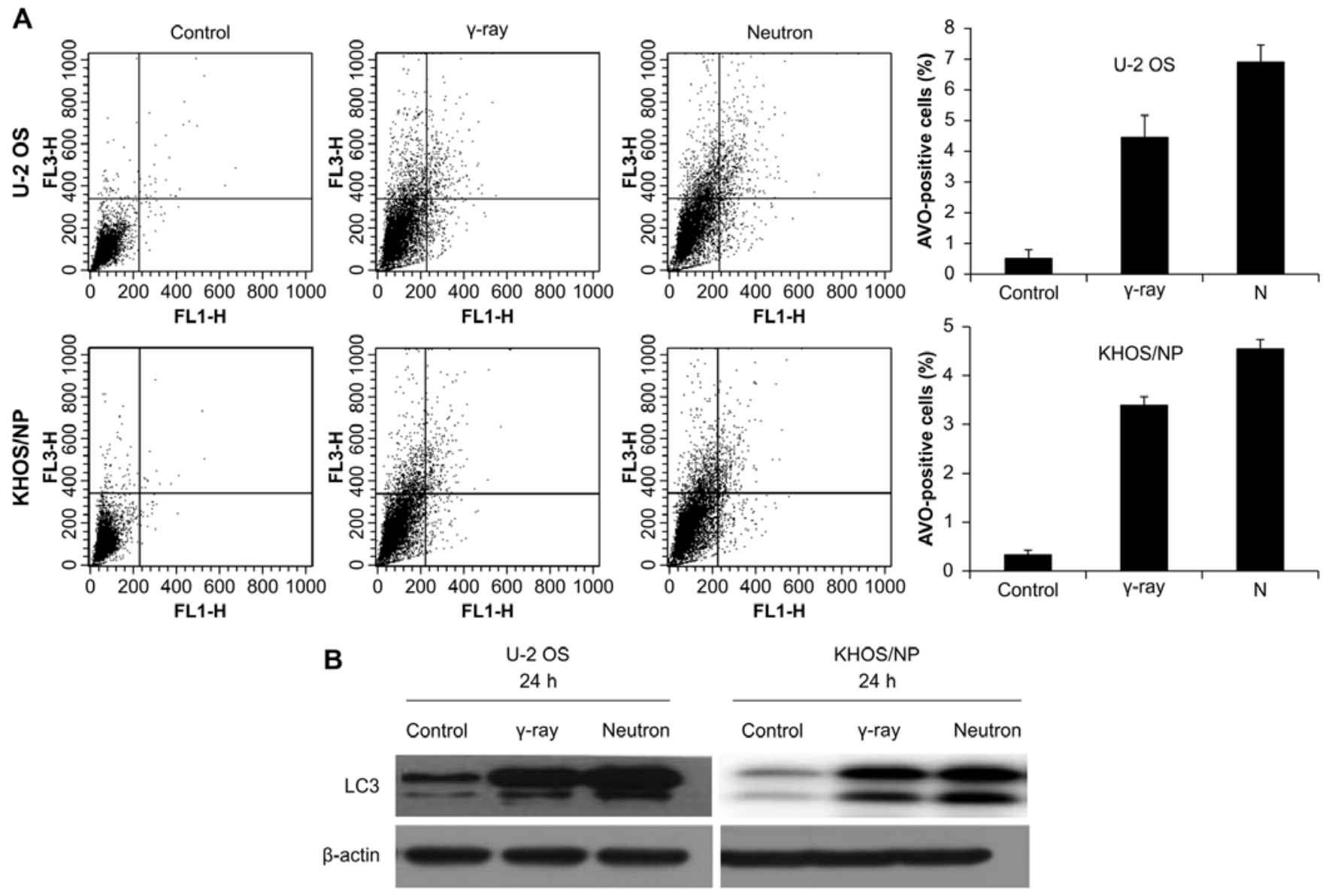

Figure 3. Analysis of autophagy after radiation in OS cells. (A) U2O2 and KHOS/NP cells were irradiated with radiation and then incubated for the indicated times. To measure acidic vesicular organelle (AVO), which is indicative of autophagy formation, cells were stained with acridine orange and analyzed quantitatively by flow cytometry. Values represent the means of 3 experiments $\pm \mathrm{SD} ;{ }^{*} \mathrm{P}<0.05,{ }^{* * *} \mathrm{P}<0.001$. (B) Cell lysates ( $30 \mu \mathrm{g}$ ) were immunoblotted (IB) with indicated antibodies.

exposure, and a more substantial effect was observed with neutron radiation (Fig. 2C). We measured radiation-induced activation of caspase- 3 and -9 protease activities. As shown in Fig. 2D, neutron radiation significantly enhanced caspase-3 and -9 as compared to that by gamma-ray radiation. Annexin V staining and caspase activation indicated that neutron irradiation-induced cell death is dependent on apoptosis induction. To investigate the relationship between ROS production and radiation-induced apoptosis, the effects of ROS production on OS cells were examined. These results revealed elevated ROS production in cells treated with high-LET radiation as compared to that in cells treated with low-LET radiation (Fig. 2E).

Effect of radiation-induced autophagy on OS cells. Autophagy was determined after irradiation by counting AVO-containing cells at given time-points (Fig. 3A). Higher increase in autophagy after neutron irradiation was demonstrated in the two cell lines. The expression of LC3 protein, which is known to be a standard indicator of autophagy, was assessed. Among two separate bands observed on western blot (an upper one of $18 \mathrm{kDa}$ for LC3-bI and a lower one of $16 \mathrm{kDa}$ for LC3-bII), the lower band representing fusion of the autophagosome to lysosome increased with increasing time after neutron irradiation (Fig. 3B).
Effect of low- or high-LET IR on DNA damage. To explore the involvement of cellular DNA repair in high-LET radiationinduced OS cytotoxicity, we analyzed the abundance of the damage-response protein, $\mathrm{H} 2 \mathrm{AX}$, by immunocytochemistry and western blotting. The number of $\gamma \mathrm{H} 2 \mathrm{AX}$ foci was initially increased $1 \mathrm{~h}$ after irradiation with either gamma-ray or neutron beams, but then substantially declined after $24 \mathrm{~h}$. The two OS cell lines treated with neutron radiation exhibited damaged DNA foci, which appeared $1 \mathrm{~h}$ after treatment exposure and were retained even $24 \mathrm{~h}$ after exposure; therefore, the effect was greater with neutron radiation than with gamma-ray irradiation (Fig. 4A and B). Moreover, neutron-irradiated cells exhibited higher degree of IR-induced $\gamma-\mathrm{H} 2 \mathrm{AX}$ staining, indicative of increased DNA damage (Fig. 4A and B). To investigate whether reduced double-stranded break (DSB) repair activity detected in IR-treated cells was due to the suppression of DSB repair-related proteins, the effect of IR treatment on the expression of key proteins in the homologous recombination (HR) and non-homologous end-joining (NHEJ) pathways was examined. The relative abundance of DNA damage repair-associated proteins in OS cells under various treatment conditions is shown in Fig. 4C. The proteins Ku70, Ku80, DNA-PKcs, NBS1, and ERCC1 were downregulated $24 \mathrm{~h}$ after neutron irradiation in U2OS cells. However, Ku70, NBS1, and ERCC1 were downregulated $24 \mathrm{~h}$ after neutron 
A
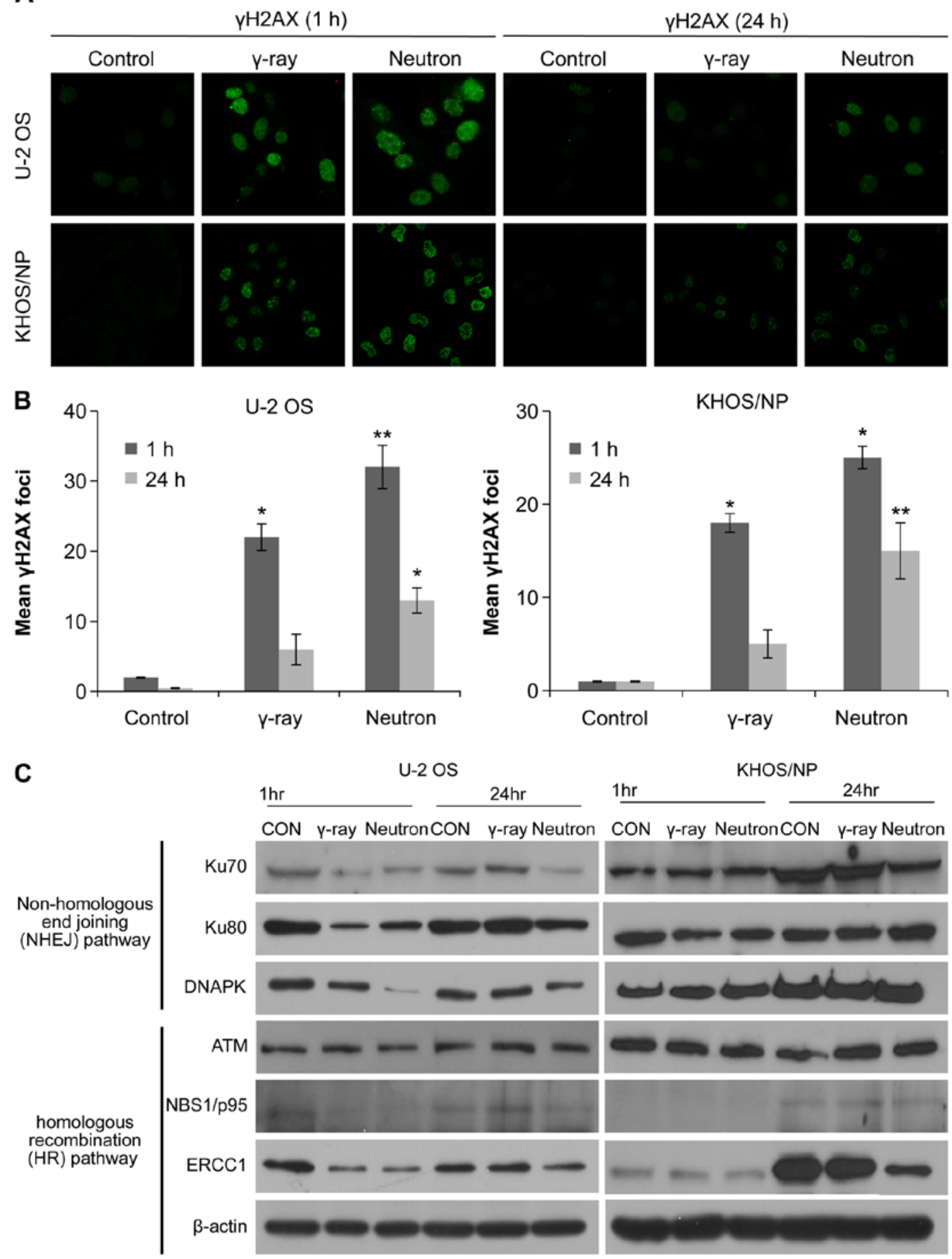

Figure 4. The effects on the DNA damage response in irradiated OS cells. (A and B) Immunocytochemistry for phosphorylated H2AX, a marker of the DNA damage response, in $\mathrm{U} 2 \mathrm{OS}$ and $\mathrm{KHOS} / \mathrm{NP}$ cells exposed to radiation at 1 and $24 \mathrm{~h}$ after irradiation. Values represent the means of 3 experiments $\pm \mathrm{SD} ;{ }^{*} \mathrm{P}<0.05$,

${ }^{* *} \mathrm{P}<0.001$. (C) Cell lysates $(30 \mu \mathrm{g})$ were immunoblotted (IB) with indicated antibodies.

irradiation in KHOS/NP cells. These results suggest that neutron irradiation inhibits the expression of both HR- and NHEJ-related proteins, inhibiting the repair of IR-induced DSBs, depending upon the cell lines.

Effect of IR on cell motility and cell invasion. Next, the effects of gamma-ray and neutron irradiation on the migratory abilities of OS cells were estimated using a scratch assay. Remarkably, compared to gamma-ray radiation, neutron radiation significantly inhibited cell migration (Fig. 5A). Matrigel invasion assay was also performed to examine the effect of IR on tumor cell invasiveness in OS cell lines, and it was found that neutron irradiation effectively inhibited tumor cell invasion (Fig. 5B).

Effects of low-or high-LET IR on orthotopic tumors in vivo. Based on these data, the therapeutic efficacy of high-LET radiation was assessed in vivo using an orthotopic mouse 
A
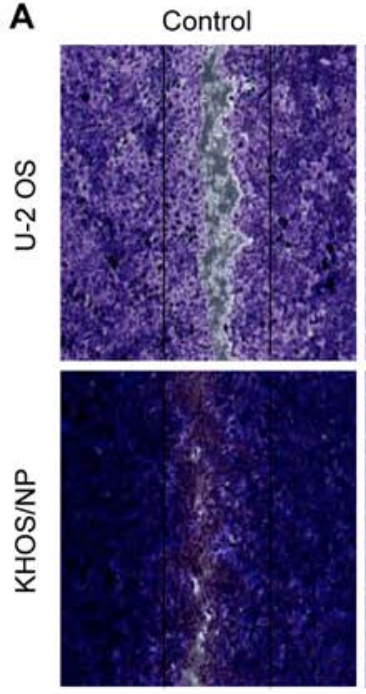

B

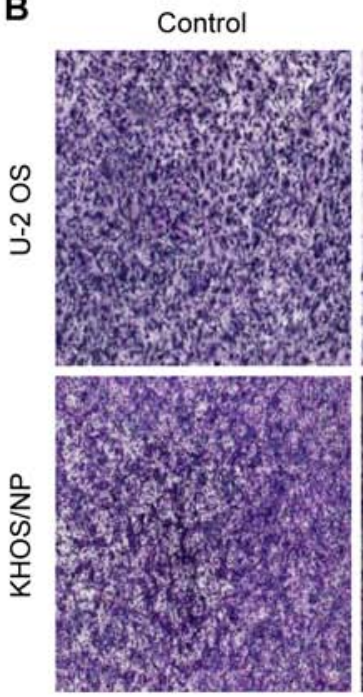

Y-ray
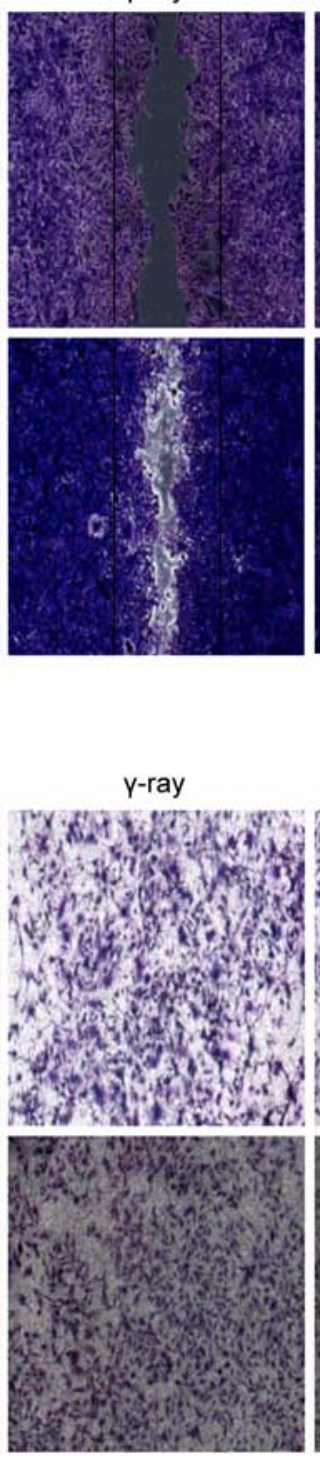

Neutron
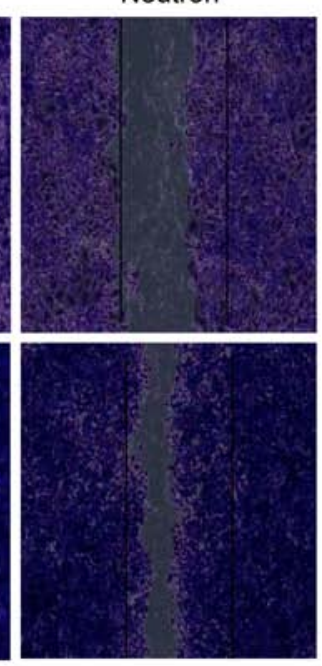

Neutron

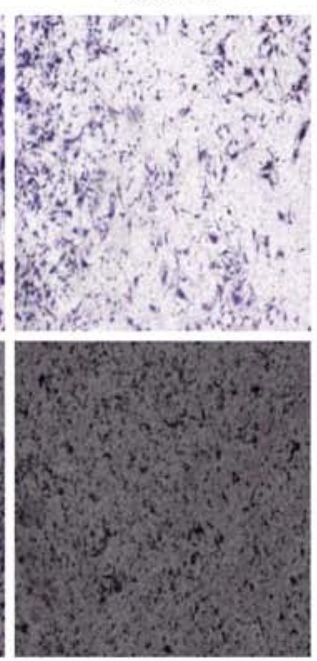

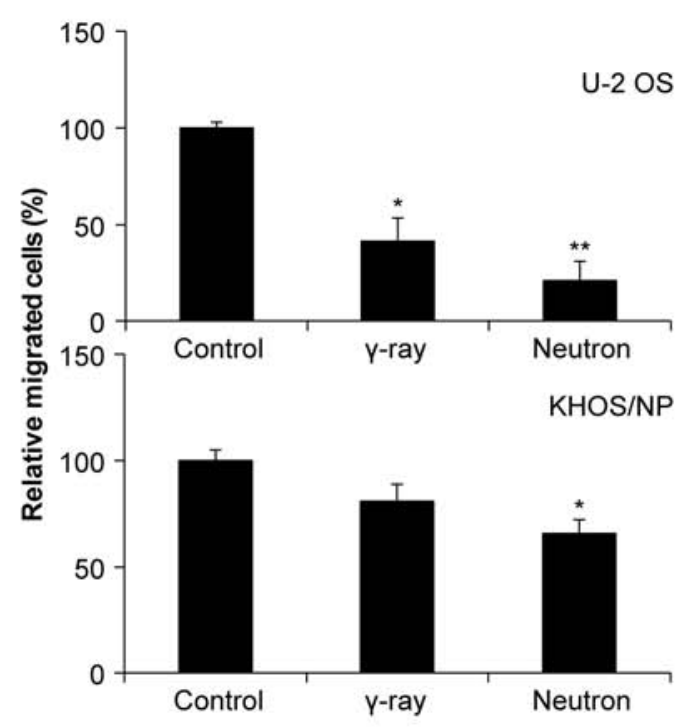

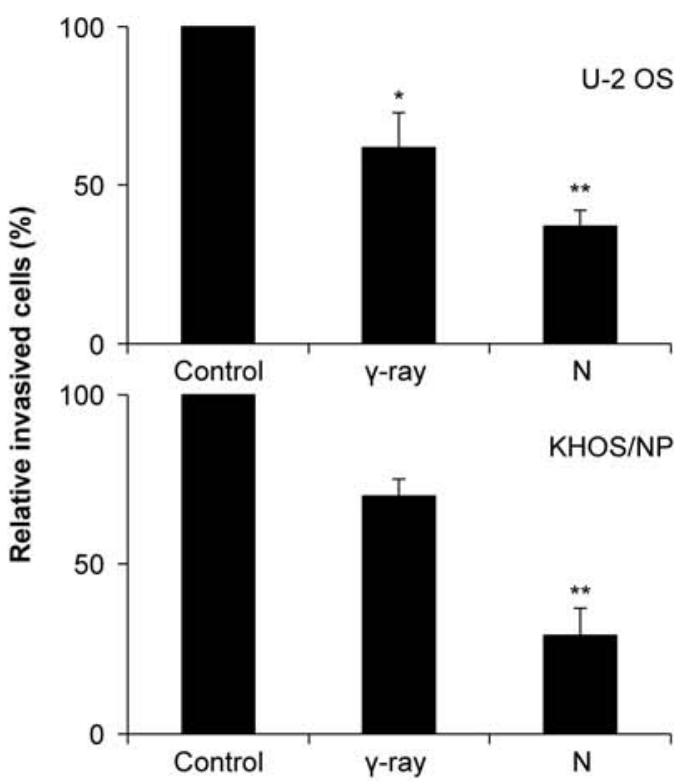

Figure 5. The effect of treatment with radiation on the invasion and migration of OS cells. (A) U2OS and KHOS/NP cells were scraped with 200- $\mu 1$ pipette tips for the scratch assay and then treated with $5 \mathrm{~Gy}$ gamma-ray and neutron radiation. After incubation for $24 \mathrm{~h}$, the number of cells that migrated across the wound was counted. Each assay was photographed, distances between the migrating cell edges were quantified, and percentage cell migration was calculated. Values represent the means of 3 experiments $\pm \mathrm{SD} ;{ }^{*} \mathrm{P}<0.05,{ }^{* *} \mathrm{P}<0.001$. (B) OS cell invasion after $24-\mathrm{h}$ IR treatment were examined by transwell chamber assays. The numbers of invading tumor cells that penetrated through Matrigel were counted and calculated in 5 high-magnification microscopy fields. Values represent the mean \pm SD of 3 experiments; ${ }^{*} \mathrm{P}<0.05,{ }^{* *} \mathrm{P}<0.001$.

model (Fig. 6A). Significantly, neutron irradiation decreased tumor growth in mice as compared to that in gamma-ray-treated mice (Fig. 6B) with no visible signs of toxicity as evidenced by the lack of a difference in body weight (Fig. 6C). Additionally, $\mathrm{H} \& \mathrm{E}$ staining revealed that tumor from high-LET radiationtreated mice showed higher apoptosis rate (Fig. 6D).

\section{Discussion}

Osteosarcomas (OSs) are primary malignant bone tumors identified by the production of osteoid or immature bone (1). These tumors generally exhibit a high potential for pulmonary metastasis and significant radioresistance (5-8). Based on this evidence, high-LET neutron and carbon ion beam radiations have been the preferred treatment modality for these patients. Preclinical evidence shows that the biological effects of IR depend on the quality-type and dose of radiation, as well as the cell or tumor type (24). High-LET radiation induces dense ionization along the particle track sufficient for highly localized DNA damage (25). Conversely, low-LET radiation beams are sparse, resulting in more diffuse, homogeneous dosing (25). Therefore, the biological effect of high-LET radiation is generally much higher than that of low-LET radiation at the same dose (26), generally, because high-LET radiation deposits most of its energy within one cell, resulting in more extensive DNA damage $(27,28)$. Thus, high-LET radiation generates more complicated and varied cellular effects; however, the molecular mechanisms underlying high-LET radiation-induced cytotoxicity remain a topic of investigation. 
A

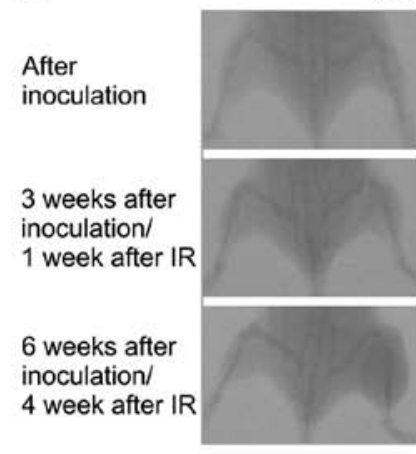

Control
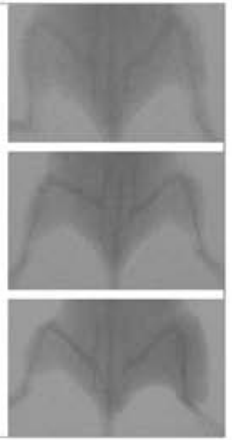

gamma-ray
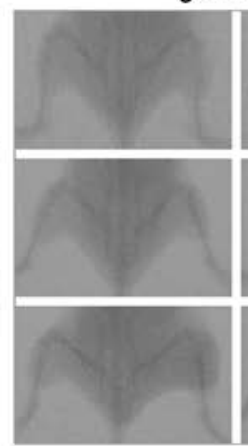
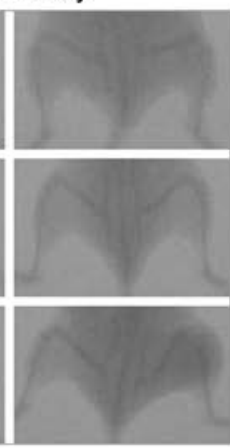
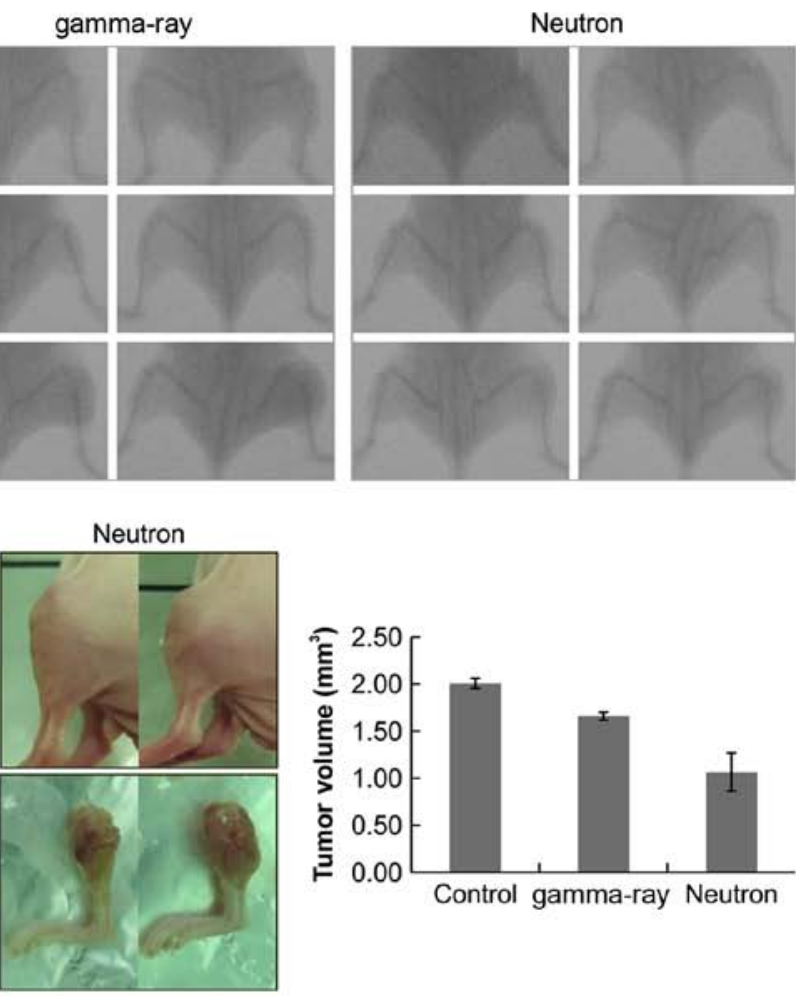

C

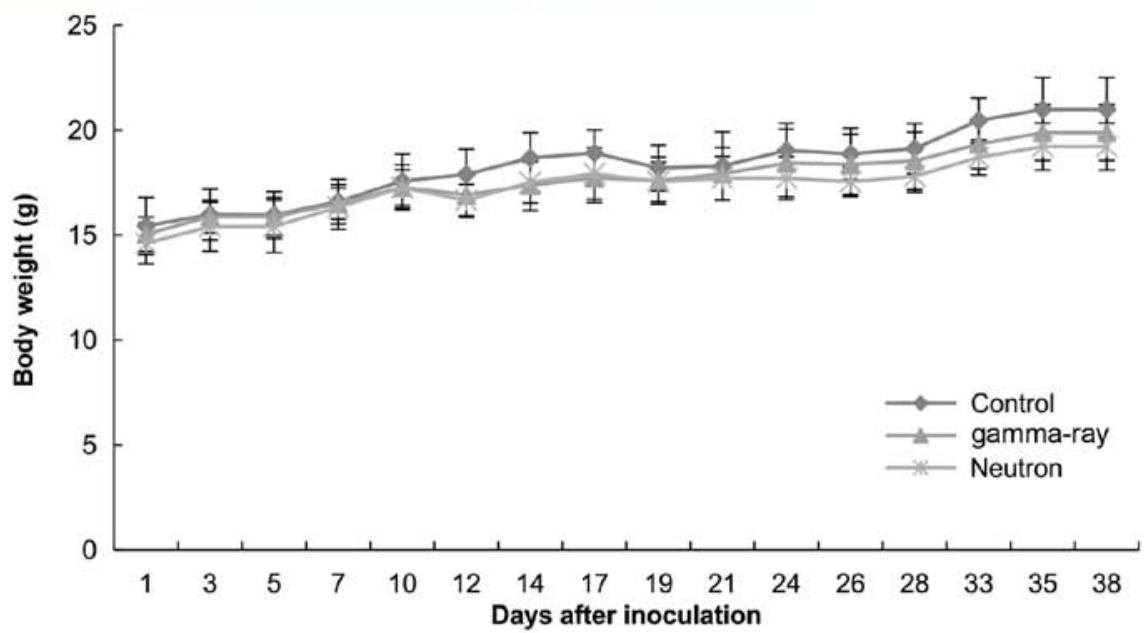

D

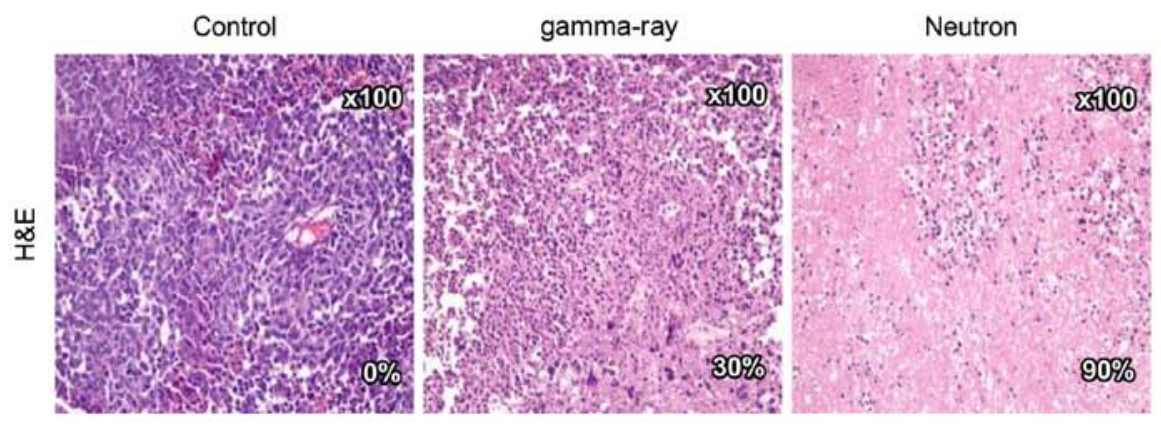

Figure 6. The effects on orthotopic tumors in vivo treated with irradiation. (A) KHOS/NP cells were injected into the proximal tibia of 2 groups each containing 4 nude mice to generate an orthotopic tumor model. The dimensions of the leg (including the tumor) were measured every 7 days by X-ray analysis. Representative radiographs of the limb of a mouse at 0 and 6 weeks after tumor inoculation are shown. (B) Representative images of animal tumors at 6 weeks and a graph of tumor size against time are shown. The dimensions of the leg (including the tumor) were measured every 3-4 days and the volume was calculated. (C) Change in body weight at each time point relative to body weight at the time of treatment. $n=3$ per group, mean \pm SD. (D) Tumors were excised and processed for immunostaining or hematoxylin and eosin (H\&E) staining. Original magnification, x100.

Herein, we investigated the effects of high- and low-LET irradiation on the two OS cell lines. Notably, high-LET radiation was significantly more effective at inhibiting OS cell proliferation and inducing caspase-3/9 activation (Figs. 1 and 2). 
Additionally, an increase in AVOs was detected by acridine orange staining of lysosomes as well as conversion of LC3B-I into LC3B-II by immunoblotting in neutron treated cells. These results supported the induction of enhanced autophagy in response to neutron radiation in OS cells compared to that with gamma-ray radiation (Fig. 3). Our results also showed that high-LET radiation results in stable free radicals and more DSBs than that observed with gamma-ray radiation. Neutron irradiation also sensitizes OS cells by interfering with the NHEJ and HR pathways, thus limiting DSB repair in OS cells (Fig. 4). Finally, we studied the metastatic effect of IR treatment and found that neutron radiation effectively inhibited invasion and migration of OS cells (Fig. 5). These unique findings improve our understanding about the indirect effects of high-LET radiation and its clinical application to patients with OS.

Orthotopic models are essential for the preclinical evaluation of therapeutic agents and they are used for studying the pathobiology of tumor progression and metastasis. Accordingly, we examined the effects of each type of irradiation on an orthotopic mouse model of OS. Tumor measurements using caliper and H\&E staining showed significantly smaller tumors with increased apoptosis in high-LET radiation-treated mice, consistent with our in vivo data (Fig. 6). However, only three medical centers worldwide use high-LET neuron radiotherapy to treat cancer, perhaps because of the difficulties in obtaining funding and regulatory approval. A potentially more viable alternative approach is to use other forms of high-LET radiation, such as carbon ion beams, which are widely used in both Japan and Europe. A previous study has shown similar RBE between neutron and carbon ion beams, but there are differences in the physical dose distribution and damage inflicted on normal tissues, which we intend to study further (10). Moreover, we believe that carbon ion beam radiotherapy results in a higher $\mathrm{RBE}$ than that with neutron beam causing less damage to normal tissues. Hence, carbon ion beam has proven to be a safe and effective modality to manage unresectable OS of the trunk, where it provides good local control and long-term functional results without ensuing morbidity $(15,16)$.

Carbon ion high-LET radiation therapy has provided dramatic local control in Japanese hospitals and has become more popular in radiation treatment. Substantial research has shown that molecular mechanisms differ between high LET and low-LET radiation. These differences should be further investigated to delineate any potential rationale or clinical utility for low- versus high-LET radiation therapy, such as neutron or carbon beam treatment, in patients with OS.

In conclusion, our study revealed that as compared to low-LET gamma-ray radiotherapy, high-LET neutron radiotherapy provided a stronger therapeutic benefit by increasing OS cell apoptosis and DNA damage in vitro and in orthotopic mouse model in vivo, and thus, it provides further preclinical rationale for high-LET radiotherapy.

\section{Acknowledgements}

This study was supported by a National Research Foundation (NRF) of Korea grant (nos. NRF-2017R1D1A1B03028923) funded by the Korean Government (MSIP) and by a grant of the Korea Institute of Radiological and Medical Sciences (KIRAMS), funded by Ministry of Science, ICT, and Future Planning, Republic of Korea (1711045557;1711045538; 1711045554/50531-2017,50473-2017).

\section{References}

1. Unni KK and Dahlin DC: Osteosarcoma: Pathology and classification. Semin Roentgenol 24: 143-152, 1989.

2. Ciernik IF, Niemierko A, Harmon DC, Kobayashi W, Chen YL, Yock TI, Ebb DH, Choy E, Raskin KA, Liebsch N, et al: Proton-based radiotherapy for unresectable or incompletely resected osteosarcoma. Cancer 117: 4522-4530, 2011.

3. Ta HT, Dass CR, Choong PF and Dunstan DE: Osteosarcoma treatment: State of the art. Cancer Metastasis Rev 28: 247-263, 2009.

4. Schwarz R, Bruland O, Cassoni A, Schomberg P and Bielack S: The role of radiotherapy in oseosarcoma. Cancer Treat Res 152: 147-164, 2009.

5. Beck JC, Wara WM, Bovill EG Jr and Phillips TL: The role of radiation therapy in the treatment of osteosarcoma. Radiology 120: $163-165,1976$.

6. DeLaney TF, Park L, Goldberg SI, Hug EB, Liebsch NJ, Munzenrider JE and Suit HD: Radiotherapy for local control of osteosarcoma. Int J Radiat Oncol Biol Phys 61: 492-498, 2005.

7. Imai R, Kamada T, Tsuji H, Tsujii H, Tsuburai Y and Tatezaki S; Working Group for Bone and Soft Tissue Sarcomas: Cervical spine osteosarcoma treated with carbon-ion radiotherapy. Lancet Oncol 7: 1034-1035, 2006.

8. Mankin HJ, Hornicek FJ, Rosenberg AE, Harmon DC and Gebhardt MC: Survival data for 648 patients with osteosarcoma treated at one institution. Clin Orthop Relat Res 429: 286-291, 2004.

9. Lisle JW, Choi JY, Horton JA, Allen MJ and Damron TA: Metastatic osteosarcoma gene expression differs in vitro and in vivo. Clin Orthop Relat Res 466: 2071-2080, 2008.

10. Skarsgard LD: Radiobiology with heavy charged particles: A historical review. Phys Med 14 (Suppl 1): 1-19, 1998.

11. Okayasu R: Repair of DNA damage induced by accelerated heavy ions - a mini review. Int J Cancer 130: 991-1000, 2012.

12. Kamada T, Tsujii H, Blakely EA, Debus J, De Neve W, Durante M, Jäkel O, Mayer R, Orecchia R, Pötter R, et al: Carbon ion radiotherapy in Japan: An assessment of 20 years of clinical experience. Lancet Oncol 16: e93-e100, 2015.

13. Kanai T, Endo M, Minohara S, Miyahara N, Koyama-ito H, Tomura H, Matsufuji N, Futami Y, Fukumura A, Hiraoka T, et al: Biophysical characteristics of HIMAC clinical irradiation system for heavy-ion radiation therapy. Int J Radiat Oncol Biol Phys 44: 201-210, 1999.

14. Zhang W, Tanaka M, Sugimoto Y, Takigawa T and Ozaki T: Carbon-ion radiotherapy of spinal osteosarcoma with long-term follow. Eur Spine J 25 (Suppl 1): 113-117, 2016.

15. Matsunobu A, Imai R, Kamada T, Imaizumi T, Tsuji H, Tsujii H, Shioyama Y, Honda H and Tatezaki S; Working Group for Bone and Soft Tissue Sarcomas: Impact of carbon ion radiotherapy for unresectable osteosarcoma of the trunk. Cancer 118: 4555-4563, 2012.

16. Futamura G, Kawabata S, Siba H, Kuroiwa T, Suzuki M, Kondo N, Ono K, Sakurai Y, Tanaka M, Todo T, et al: A case of radiation-induced osteosarcoma treated effectively by boron neutron capture therapy. Radiat Oncol 9: 237, 2014.

17. Lee DH, Seo SH and Ji YH: Characteristics of radiation generated by BNCT irradiator of Hanaro nucleasr reactor. J Korean Soc Ther Radiol Oncol 24: s158, 2006.

18. Eom KY, Wu HG, Park HJ, Huh SN, Ye SJ, Lee DH and Park SW: Evaluation of biological characteristics of neutron beam generated from MC50 cyclotron. J Korean Soc Ther Radiol Oncol 24: 280-284, 2006.

19. Luu HH, Kang Q, Park JK, Si W, Luo Q, Jiang W, Yin H, Montag AG, Simon MA, Peabody TD, et al: An orthotopic model of human osteosarcoma growth and spontaneous pulmonary metastasis. Clin Exp Metastasis 22: 319-329, 2005.

20. Song WS, Jeon DG, Cho WH, Kong CB, Cho SH, Lee SY and Lee SY: Spontaneous necrosis and additional tumor necrosis induced by preoperative chemotherapy for osteosarcoma: A case-control study. J Orthop Sci 20: 174-179, 2015. 
21. Kong CB, Byun BH, Lim I, Choi CW, Lim SM, Song WS, Cho WH, Jeon DG, Koh JS, Yoo JY, et al: ${ }^{18}$ F-FDG PET SUVmax as an indicator of histopathologic response after neoadjuvant chemotherapy in extremity osteosarcoma. Eur J Nucl Med Mol Imaging 40: 728-736, 2013.

22. McIlwain DR, Berger T and Mak TW: Caspase functions in cell death and disease. Cold Spring Harb Perspect Biol 5: a008656, 2013

23. Los M, Mozoluk M, Ferrari D, Stepczynska A, Stroh C, Renz A Herceg Z, Wang ZQ and Schulze-Osthoff K: Activation and caspase-mediated inhibition of PARP: A molecular switch between fibroblast necrosis and apoptosis in death receptor signaling. Mol Biol Cell 13: 978-988, 2002.

24. Goodhead DT, Thacker J and Cox R: Weiss Lecture. Effects of radiations of different qualities on cells: Molecular mechanisms of damage and repair. Int J Radiat Biol 63: 543-556, 1993.
25. Goodhead DT: Energy deposition stochastics and track structure: What about the target? Radiat Prot Dosimetry 122: 3-15, 2006.

26. Anderson RM, Marsden SJ, Wright EG, Kadhim MA, Goodhead DT and Griffin CS: Complex chromosome aberrations in peripheral blood lymphocytes as a potential biomarker of exposure to high-LET alpha-particles. Int J Radiat Biol 76: 31-42, 2000.

27. Brenner DJ and Ward JF: Constraints on energy deposition and target size of multiply damaged sites associated with DNA double-strand breaks. Int J Radiat Biol 61: 737-748, 1992.

28. Tanaka K, Gajendiran N, Endo S, Komatsu K, Hoshi M and Kamada N: Neutron energy-dependent initial DNA damage and chromosomal exchange. J Radiat Res (Tokyo) 40 (Suppl): S36-S44, 1999. 